\begin{tabular}{|c|l|}
\hline Title & $\begin{array}{l}\text { Mechanisms determining relationships between feeding group size and foraging success in food patch use by Japanese } \\
\text { macaques (Macaca fuscata) }\end{array}$ \\
\hline Author(s) & Kazahari, Nobuko; A getsuma, Naoki \\
\hline Citation & $\begin{array}{l}\text { Behaviour, 147(11), 1481-1500 } \\
\text { https://doi.org/10.1163/000579510X 521573 }\end{array}$ \\
\hline Issue Date & 2010 \\
\hline Doc URL & http://hdl.handle.net/2115/51738 \\
\hline Type & article (author version) \\
\hline File Information & Kazahari \& A getsuma (2010)2.pdf \\
\hline
\end{tabular}

Instructions for use 


\title{
Mechanisms determining relationships between feeding group size and foraging success in food patch use by Japanese macaques (Macaca fuscata)
}

\author{
Nobuko Kazahari ${ }^{1,2,3}$ \& Naoki Agetsuma 2
}

('Wildlife Research Center, Kyoto University, Kyoto, Japan; ' Field Science Center for Northern Biosphere, Hokkaido University, Sapporo, Japan)

(Accepted: 2 July 2010)

Summary

We evaluated the effects of social monitoring and feeding competition on foraging success in relation to the feeding group size of wild Japanese macaques (Macaca fuscata). Social monitoring is visual scanning by group members that assists them in following their own group. Individuals in smaller feeding groups may frequently use social monitoring while foraging, because they have an increased risk of losing their group. Therefore, social monitoring could be a cost for group-foraging animals. We made four predictions: (1) individuals in smaller feeding groups tend to abandon food patches to follow group members; (2) social monitoring frequency is higher in smaller feeding groups; (3) feeding rate decreases with increased social monitoring frequency; and (4) feeding rate initially increases with feeding group size because decreased social monitoring outweighs increased feeding competition, but after the feeding group reaches a certain size, feeding rate declines with increasing feeding group size due to the high costs of feeding competition. These predictions were supported by our results. Thus, the relationship between feeding group size and feeding rate can show three patterns (positive, neutral and negative) in response to the balance between the costs of social monitoring and feeding competition.

Keywords: feeding competition, feeding group size, foraging success, patch use, social monitoring.

\section{Introduction}

The costs of group-living on foraging have played important roles in the evolution of primate groups (Wrangham, 1980; van Schaik, 1983). Generally, sharing food resources with other group members causes within-group feeding competition, which reduces the foraging success of individuals within the group (Janson, 1988; Janson \& van Schaik, 1988). Then, the within-group feeding competition increases with increasing group size (Wrangham, 1980; van Schaik, 1983; Janson \& Goldsmith, 1995; Steenbeek \& van Schaik, 2001). However, individuals in a group have some benefits in terms of the efficient discovery of food patches (Clark \& Mangel, 1986) and protection from predators (Terborgh, 1983; van Schaik \& van Hooff, 1983).

Many primate species depend on patchily distributed fruits and leaves as food sources (Leighton \& Leighton, 1982; Nakagawa, 1989; Agetsuma, 1995a). However, group members may not always stay together in a food patch (Whitten, 1988; Agetsuma, 1995b), and may split into several temporary feeding groups (fission-fusion societies: Leighton \& Leighton, 1982; de Moraes et al., 1998; cohesive societies: 
Whitten, 1988). Although the relationship between feeding group size and feeding rate in food patches has been extensively studied (e.g., Leighton \& Leighton, 1982; Chapman, 1988; Furuichi \& Hashimoto, 2007), the effects of group size on feeding success remain unclear. For example, the feeding rate of red colobus monkeys (Piliocolobus tephrosceles) decreases with feeding group size because of scramble feeding competition (Snaith \& Chapman, 2005), whereas the feeding rate of vervet monkeys (Chlorocebus aethiops) is not influenced by feeding group size (Whitten, 1988). Whitten (1988) assumed that the monkeys adjust their feeding group size to food patch capacity. Moreover, at our study site on Kinkazan Island, Japan, the feeding rate of Japanese macaques (Macaca fuscata) increases with feeding group size (Kazahari \& Agetsuma, 2008). The presence of other individuals may improve foraging success by reducing the need for vigilance against predators (Berger, 1978; Caraco, 1979; Sullivan, 1984) and the defense of food resources from other groups (i.e., inter-group feeding competition; Wrangham, 1980). However, for Japanese macaques on Kinkazan Island, no predators are present, and inter-group encounters rarely occur. Therefore, other mechanisms, which have not been previously examined, must be involved in the foraging success of group-living animals (Kazahari \& Agetsuma, 2008). The detection of such mechanisms could resolve the apparently conflicting results on the relationship between feeding group size and foraging success (Whitten, 1988; Snaith \& Chapman, 2005; Kazahari \& Agetsuma, 2008).

The costs and benefits of staying in proximity to other group members affect the relationship between feeding group size and feeding rate. Primate group members must stay within a range of group dispersion to avoid losing their group (van Schaik, 1989). They must visually confirm the movements of other members (i.e., social monitoring) to determine their own next behavior (Emery et al., 1997). Japanese macaques engage in frequent social monitoring to confirm the spatial locations of group members when groups are dispersed (Suzuki, 2006).Without social monitoring, they may lose their group. When Japanese macaques lose their group, they tend to move around and make many long-distance calls until they relocate the group (Kazahari personal observation), incurring energy and time costs. Therefore, even during foraging, individuals must monitor the movements of other group members. Thus, social monitoring may have negative effects on foraging success. Foraging success is also reduced through direct competition by aggressive interactions and dominance rank (contest competition), and through indirect competition by the sharing of food resources with other group members (scramble competition; Janson \& van Schaik, 1988). Both types of feeding competition increase with group size (Wrangham, 1980; van Schaik, 1983; Janson, 1985; Janson \& Goldsmith, 1995; Steenbeek \& van Schaik, 2001; Vogel \& Janson, 2007).

We present the following hypothesis to describe the relationship between feeding group size and feeding rate. Feeding rate depends on two types of cost: the cost of social monitoring and the cost of feeding competition, which vary in opposing ways with feeding group size. Although feeding competition increases in larger groups (Wrangham, 1980; van Schaik, 1983; Janson, 1985; Janson \& Goldsmith, 1995; Steenbeek \& van Schaik, 2001; Vogel \& Janson, 2007), social monitoring decreases with increasing 
feeding group size. As individuals in smaller feeding groups are at increased risk of losing their own group, they need to frequently monitor the movements of other group members and must sometimes even abandon food patches to follow other members. When feeding group size grows above a certain level, individual social monitoring may become unnecessary. Thus, the cost of social monitoring may decrease with feeding group size only to a certain level, whereas the cost of feeding competition increases continuously with increasing feeding group size.

Based on this hypothesis, the actual feeding rate at a given feeding group size depends on the combined costs of social monitoring and feeding competition. We expect feeding rate to be maximized when these combined costs are minimized. Combined costs may be large in the smallest and largest feeding groups due to the substantial costs of social monitoring and feeding competition, respectively. Thus, we predicted a parabolic relationship between feeding group size and feeding rate, which would enable the identification of an optimal feeding group size for feeding rate.

From our hypothesis, we made the following predictions: Prediction 1, individuals in smaller feeding groups tend to give up food patches to follow other group members; Prediction 2, social monitoring frequency is higher in smaller feeding groups; Prediction 3, feeding rate decreases with social monitoring frequency; and Prediction 4, the relationship between feeding rate and feeding group size is expressed as a parabolic curve. We examined these four predictions to verify our hypothesis.

By focusing on the costs of both social monitoring and feeding competition, we expect to explain the reason for the inconsistent findings of previous studies on the relationship between feeding group size and foraging success (Whitten, 1988; Snaith \& Chapman, 2005; Kazahari \& Agetsuma, 2008). Ultimately, this study contributes to the understanding of foraging success in group-living animals.

\section{Methods}

Study site and subjects

The study was conducted on Kinkazan Island $(10 \mathrm{~km} 2)$, northern Japan (38.16_N, 141.35_E). The island is covered with a mixed forest of coniferous and broad-leaved trees (Yoshii \& Yoshioka, 1949). Trees are sparse, due to high feeding pressure from sika deer (Cervus nippon Yoshii \& Yoshioka, 1949). Therefore, macaques tend to move across the ground between food trees. Thus, each food tree can be defined as a food patch (Nakagawa, 1990). Six groups of Japanese macaques live on the island, with a total population size of 221 (Izawa, 2005). We studied the $B_{1}$ troop, which consisted of 13 adult females ( $\geqq 7$ years old), 2 adult males ( $\geqq 7$ years old) and 6 juveniles ( $1-4$ years old). Japanese macaques have a linear dominance hierarchy among females, which is nepotistic (Kawamura, 1965). Dominance rank affects the foraging success of group-living primates through contest feeding competition (Janson \& van Schaik, 1988). Four adult females, with respective dominance ranks of 1, 6, 9 and 13, were chosen as study subjects to evaluate the degree of contest feeding competition. The intensity of contest competition varies with food 
patch size (Mitchell et al., 1991), patch distribution (Barton, 1993), the amount of food, and its relative availability (Saito, 1996). Japanese macaques sometimes greatly change the composition of their diets within a period of 2 weeks in response to changes in food conditions (Agetsuma, 1995c), and in such cases the intensity of feeding competition must vary over the same time scale. Thus, it was necessary to select a rather short observation period during which the macaques depended mainly on one food item to minimize changes in food conditions. In this study, we chose an observation period from 14 to 27 April 2005. During this period, the macaques depended on flowers of the Japanese beech (Fagus crenata) for $57 \%$ of their total foraging time. The energy content of one bite of the flowers was about twice as high as the energy content of the other two main food items eaten during the period (Tsuji, unpublished data), i.e., Berberis thunbergii leaves (21\% of total foraging time) and herbaceous plants (13\%). The beech trees were distributed relatively uniformly within the range of the macaque group at a density of 16.4 trees/ha, which was higher than the densities of other food tree species (Kazahari \& Agetsuma, data not shown). We did not observe any encounters between the $B_{1}$ troop and neighbouring troops. No macaque predators inhabit the island (Izawa, 1983).

\section{Foraging behaviour and feeding group size}

We collected behavioural data using the focal animal sampling method (Altmann, 1974). Each day, one of the four females was selected as the target and followed from dusk to dawn. While following the focal female, we collected behavioural data continuously during each 8-min observation session (Kazahari \& Agetsuma, 2008). For the first half of the session (behaviour sampling sub-session), we recorded the number of seconds spent engaging in three behaviours: foraging, travelling and inactivity, including resting and self- and social grooming. When possible, we also counted the number of flowers consumed while foraging in beech trees (food patches). The time spent feeding (handling and chewing) on the flowers was recorded in seconds. We defined social monitoring as visual scanning lasting for more than $1 \mathrm{~s}$ to confirm the spatial location of other group members around food trees. Macaques sometimes conduct visual scanning to search for food items in a food patch, but neither visual scanning of the upper branches of food trees nor visual scanning related to other events, such as agonistic interactions and the approach of other individuals, were treated as social monitoring in this study. We also counted aggression between the focal female and other individuals (e.g., attack and replacement after approach within $1 \mathrm{~m}$ ). In the second half of each session (feeding group size sampling sub-session), the number of other individuals in the same food patch (tree) with the focal female were counted to generate the feeding group size. Data collected during each sub-session (behaviour and feeding group size sampling) were treated as data from the same session. The length of observation sessions ( $8 \mathrm{~min}$ ) was set arbitrarily and operationally. However, within an 8-min period, focal females generally tended to maintain their foraging rate in a food patch, and feeding group size did not vary greatly. It was considered reasonable to treat data collected in each sub-session (behavioural and feeding group size) as one session's data. 
Other behavioural data were recorded by ad libitum sampling (Altmann, 1974). We recorded the times of entrance into and departure from food patches by the focal female. When other group members arrived at or departed from the food patches used by focal females, these times were recorded to assess the feeding group size when the focal female left the patch. We also recorded incidents when aggression from other individuals made the focal female abandon the food patch. If the focal female began feeding on foods other than beech flower during the feeding group size sub-session, we recorded the time of the switch and the food species consumed.

Observations were conducted for a total of 6-12 $\mathrm{h}$ (44-90 sessions) during an observation day, and we observed each female for 15-20 h (111-148 sessions) during the study period. The total observation time for the four females combined was $71 \mathrm{~h}$ (531 sessions). In the food patches, focal females spent $94 \%$ of the total observation time feeding during behaviour sub-sessions. We were able to count the number of flowers eaten for $84 \%$ of the total feeding time. The number of consumed flowers, feeding time, and occurrences of social monitoring were calculated for each session to analyze the effects of social monitoring on feeding rate.

\section{Food patch quality}

Foraging success is affected by food patch quality (Whitten, 1988) as well as by social factors. We assumed that patch quality was represented by the crown volume of food trees (Kazahari \& Agetsuma, 2008).We measured the maximum and minimum crown widths and depths of beech trees used by the focal animals. The crown volume of each tree was estimated as the volume of an elliptical cylinder, with the maximum and minimum widths as the major and minor axes and the depth as the height.

\section{Data analysis}

Causes of patch departure

Individuals leave food patches for several reasons: aggression from other individuals (aggression), feeding satiation (satiation), patch depletion and following other group members (following; Nakagawa, 1990). When a focal female left immediately after being attacked by other individuals, we classified the cause of patch departure as 'aggression'. When the focal female was inactive after patch departure, the cause of patch departure was classified as 'satiation'. In cases of 'patch depletion' and 'following' group members, individuals were not satiated and would try to forage after patch departure. However, discriminating 'patch depletion' from 'following' was not simple, as individuals may leave a patch due to patch depletion, but may occasionally follow other members from the patch. In foraging theory, a decrease in feeding rate suggests patch depletion (Charnov, 1976; Parker, 1978). Nakagawa (1990) suggested that patch depletion can be identified by both a reduction in feeding rate in the patch and the resumption of foraging after patch departure. In this study, we considered individuals to have left a patch due to 'patch depletion' 
when a reduction in feeding rate could be observed. If individuals left a food patch without a reduction in feeding rate, the cause of patch departure was classified as 'following'. Thus, we classified 'patch depletion' and 'following' based on the combination of behaviour after patch departure and changes in feeding rate in the patch (Figure 1). The feeding rate in each session was calculated by dividing the number of beech flowers consumed by the feeding time. We focused on changes in feeding rate by comparing the feeding rate during the last session to that during the first session for each food patch visited. When the feeding rate in the last session was $<80 \%$ of that of the first, we assumed that a reduction in feeding rate had occurred. When the focal female moved and entered a new food patch within 8 min after leaving a patch where feeding rate had been reduced, we classified the cause of patch departure as 'patch depletion'. When the focal female left the patch without feeding rate reduction, and moved or entered a new patch, the cause of patch departure was classified as 'following' group members.

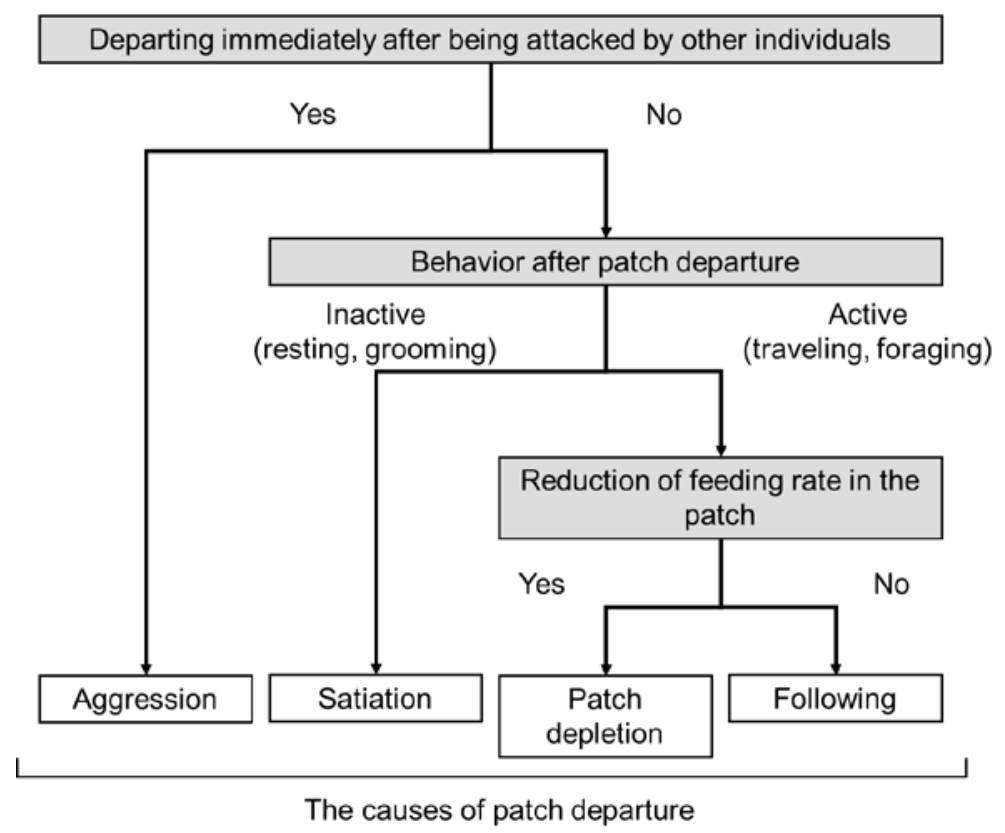

Figure 1. Classification criteria for the causes of patch departure.

Relationship between feeding group size and probability of 'following' (Prediction 1)

We examined the relationship between feeding group size and the occurrence of patch departure due to 'following' group members using a generalized linear model (GLM). This analysis allowed us to test whether the probability of 'following' increases in smaller feeding groups. Table 2 provides information about the variables used in the analysis. If over-dispersion occurred, the significance of the independent variables was estimated again by GLM with a quasi-binomial error distribution. We used the R.2.10.0 statistical package (http://www.r-project.org/) for all analyses. 
Relationship between social monitoring and feeding group size (Prediction 2)

GLM was used to test the relationship between feeding group size and social monitoring frequency (i.e., the number of occurrences of social monitoring per feeding time) for each session (Table 1). Social monitoring frequency may also be affected by dominance rank. Thus, feeding group size, dominance rank, and interaction between feeding group size and dominance rank were included in the GLM. We did not set each individual (monkey ID) as a random effect in the GLM, because the dominance rank corresponded to monkey ID. If over-dispersion occurred, the significance of the independent variables was estimated again by GLM with a quasi-Poisson error distribution.

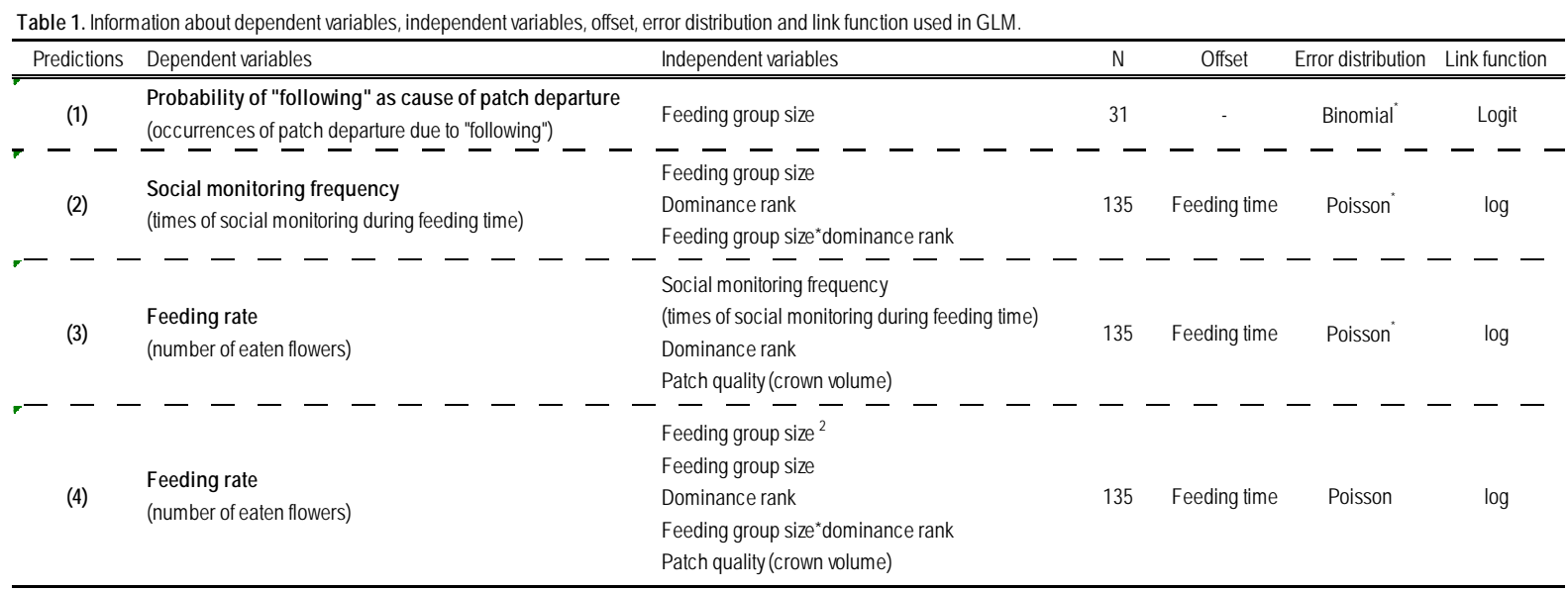

*Significant of independent variables were estimated by GLM with quasipoisson error or quasibinomial error if there were overdispersion.

Relationship between feeding rate and social monitoring (Prediction 3)

GLM was used to test the relationship between social monitoring frequency and feeding rate (i.e., number of flowers eaten per feeding time) for each session (Table 1). Feeding rate may also be affected by patch quality (Whitten, 1988) and dominance rank (Janson \& van Schaik, 1988). Thus, these factors were also included as independent variables in the GLM. We did not set monkey ID as a random effect in the GLM, because the dominance rank corresponded to monkey ID. If over-dispersion occurred, the significance of the independent variables was estimated again by GLM with a quasi-Poisson error distribution.

Relationship between feeding rate and feeding group size (Prediction 4)

We evaluated the effect of social factors on feeding rate using model selection (Table 1). Based on our hypothesis, we expected a parabolic relationship between feeding group size and feeding rate. We included both the square and linear terms of feeding group size in the GLM as independent variables. Dominance rank also affects feeding rate through contest feeding competition (Janson \& van Schaik, 1988). Moreover, the increase in contest competition with feeding group size was expected to be intense 
for lower-ranking females, as subordinate individuals were prevented from feeding in preferred sites, which allow for higher feeding rates (Janson, 1985). Therefore, we set dominance rank and interaction between dominance rank and feeding group size as the independent variables. In addition, we set patch quality as an independent variable, because patch quality tends correlate with feeding rate (Whitten, 1983). We did not set monkey ID as a random effect in the GLM, because the dominance rank corresponded to monkey ID. The best model was determined by removing the independent variables that did not improve the Akaike's information criterion compared to the full model.

\section{Results}

Relationship between feeding group size and probability of 'following'(Prediction 1)

We observed 32 cases of patch departures during the study period. For 31 cases, we were able to classify the cause of the departure (aggression $=4$, satiation $=18$, patch depletion $=1$, following $=8$, Figure 2 ). Departure due to 'patch depletion' was observed only once, and the feeding group size at departure was the largest among all cases of patch departure observed. We estimated the probability of 'following' being the cause of patch departure for each feeding group size (i.e., occurrence of patch departure by 'following') by GLM. The significance of the independent variables was estimated again by GLM with a quasi-binomial error distribution because over-dispersion was observed. There was a significant negative coefficient of feeding group size in GLM (Table 2). The probability of 'following' was higher in smaller feeding groups (Figure 3). Thus, individuals in small feeding groups tended to leave food patches by following other group members.

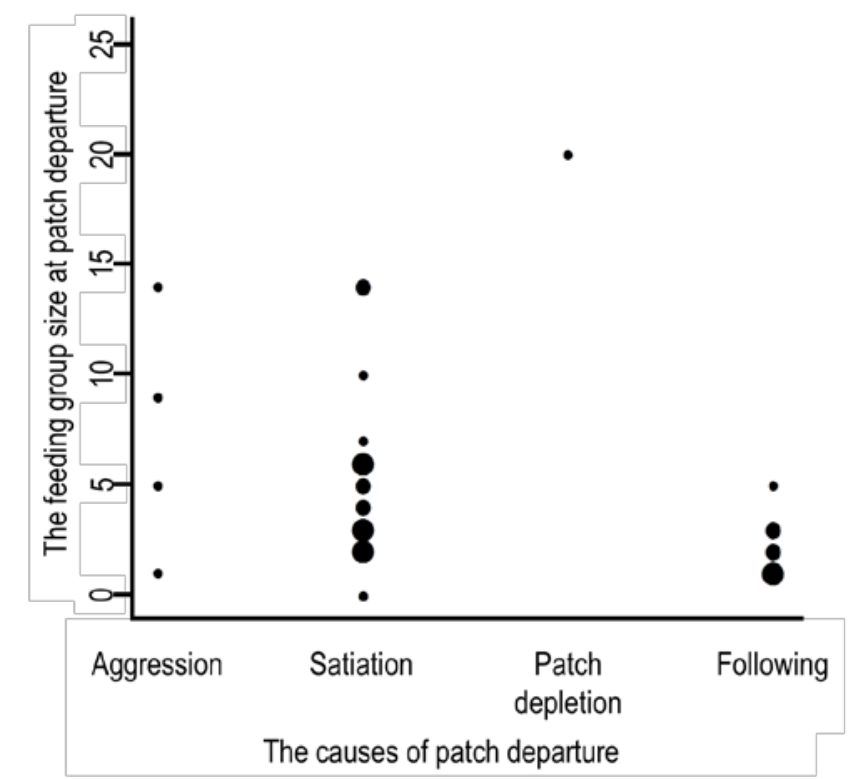

Figure 2. Relationship between feeding group size and causes of patch departure. Circle size indicates number of occurrences: small, once; intermediate, twice; large, three times. 
Table 2. Summary for GLM for predictions.

\begin{tabular}{lllccc}
\hline Prediction & Dependent variables & Independent variables & Estimate & SE & $p$ \\
\hline \hline (1) & Probability of "following" as cause of & Intercept & 0.785 & 0.791 & 0.329 \\
& patch departure & Feeding group size & -0.525 & 0.248 & $<0.05$ \\
(2) & \multirow{3}{*}{ Social monitoring frequency } & Intercept & -5.127 & 0.586 & $<0.001$ \\
& & Feeding group size & -0.298 & 0.132 & 0.024 \\
& & Dominance rank & -0.068 & 0.071 & 0.338 \\
& Feeding rate & Feeding group size x dominance rank & 0.015 & 0.014 & 0.265 \\
& & & & \\
(3) & Intercept & -0.550 & 0.035 & $<0.001$ \\
& & Social monitoring frequency & -0.085 & 0.028 & 0.002 \\
& & Dominance rank & -0.004 & 0.004 & 0.358 \\
& & Patch quality & 0.000 & 0.000 & 0.074 \\
(4) & Intercept & -0.781 & 0.081 & $<0.001$ \\
& & Feeding rate & -0.003 & 0.001 & $<0.001$ \\
& & Feeding group size & 0.057 & 0.018 & $<0.001$ \\
& & Dominance rank & 0.000 & 0.009 & 0.998 \\
& & Dominance rank $\times$ Feeding group size & -0.001 & 0.001 & 0.09 \\
& & Patch quality & 0.000 & 0.000 & 0.055 \\
\hline
\end{tabular}

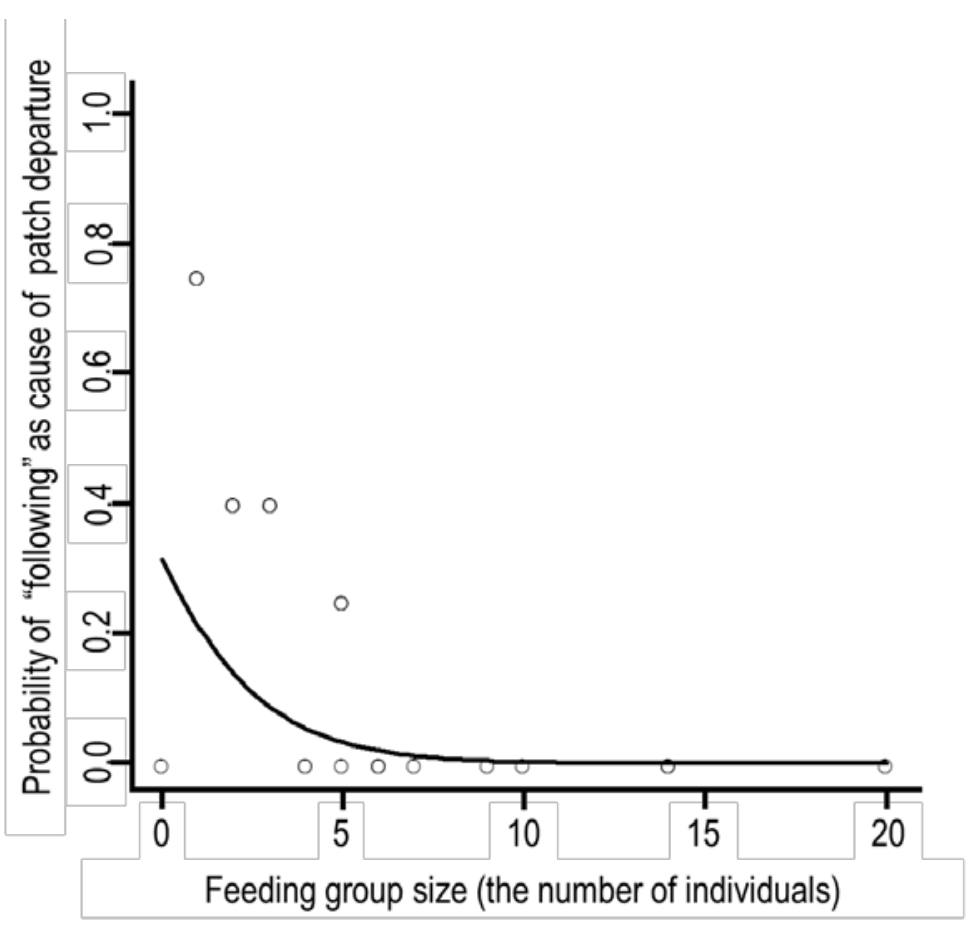

Figure 3. Relationship between feeding group size and occurrence of departing a food patch due to 'following' other group members. Circles represent observed frequency (occurrence of departure to follow group members/total occurrences of patch departure) in each feeding group size, and the line represents the estimated probability of 'following' as a cause of patch departure by GLM. 
Relationship between social monitoring and feeding group size (Prediction 2)

We tested the relationship between social monitoring frequency and feeding group size for each session. Feeding group size showed a significantly negative relationship with increased social monitoring frequency (Table 2). Social monitoring was not observed in feeding groups composed of more than 10 individuals (Figure 4). However, dominance rank and the interaction between dominance rank and feeding group size did not have significant effects on social monitoring frequency.

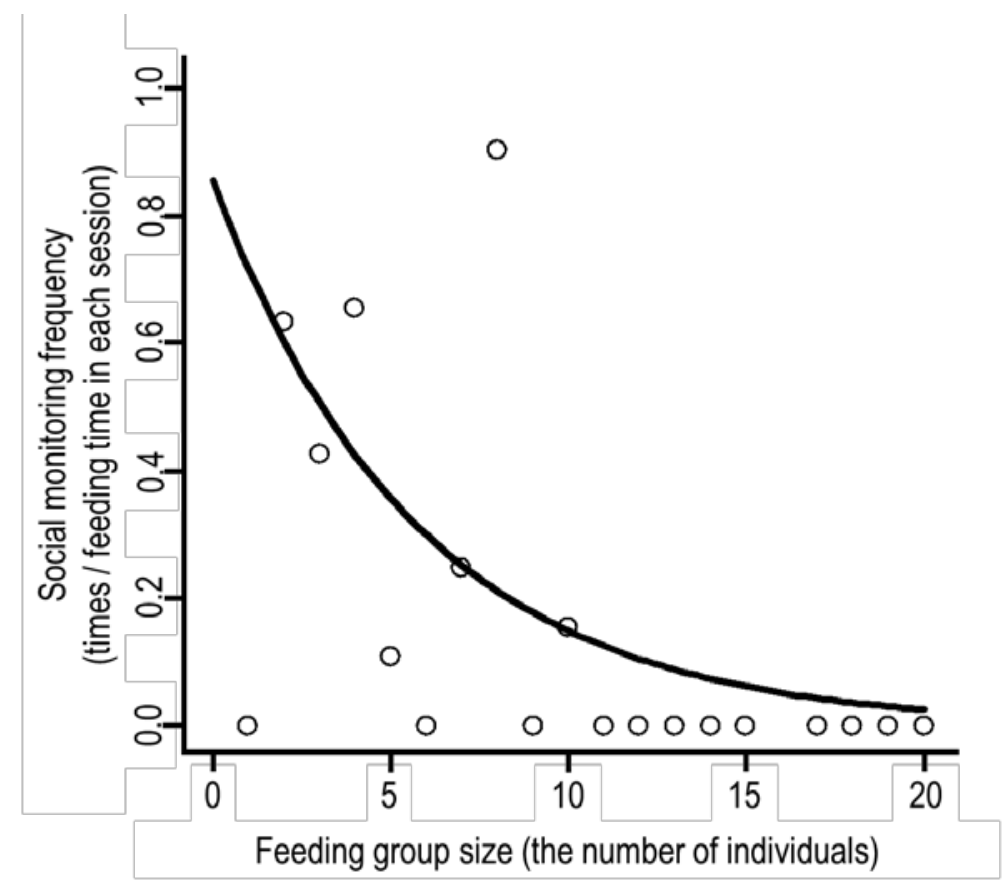

Figure 4. Relationship between social monitoring frequency (total times per total feeding time) and feeding group size. Circles represent observed frequency (times/feeding time in each session), and the line represents the values estimated by GLM.

Relationship between feeding rate and social monitoring (Prediction 3)

We also tested the relationships between social monitoring frequency, dominance rank and patch quality with feeding rate for each session. The significance of the independent variables was estimated again by GLM with a quasi-Poisson error distribution because over-dispersion was observed. Feeding rate significantly decreased with increased social monitoring frequency (Table 2), but neither dominance rank nor patch quality had significant effects on feeding rate.

Relationship between feeding rate and feeding group size (Prediction 4)

We evaluated the effects of feeding group size, dominance rank, interaction between feeding group size 
and dominance rank, and patch quality on feeding rate using model selection in GLM analysis. The full model was selected as the best model (Table 2). The relationship between feeding rate and feeding group size was expressed by a parabolic curve with an axis at around 10 individuals in a feeding group (Figure 5). Thus, the maximum feeding rate was achieved when the feeding group was composed of approx. 10 individuals.

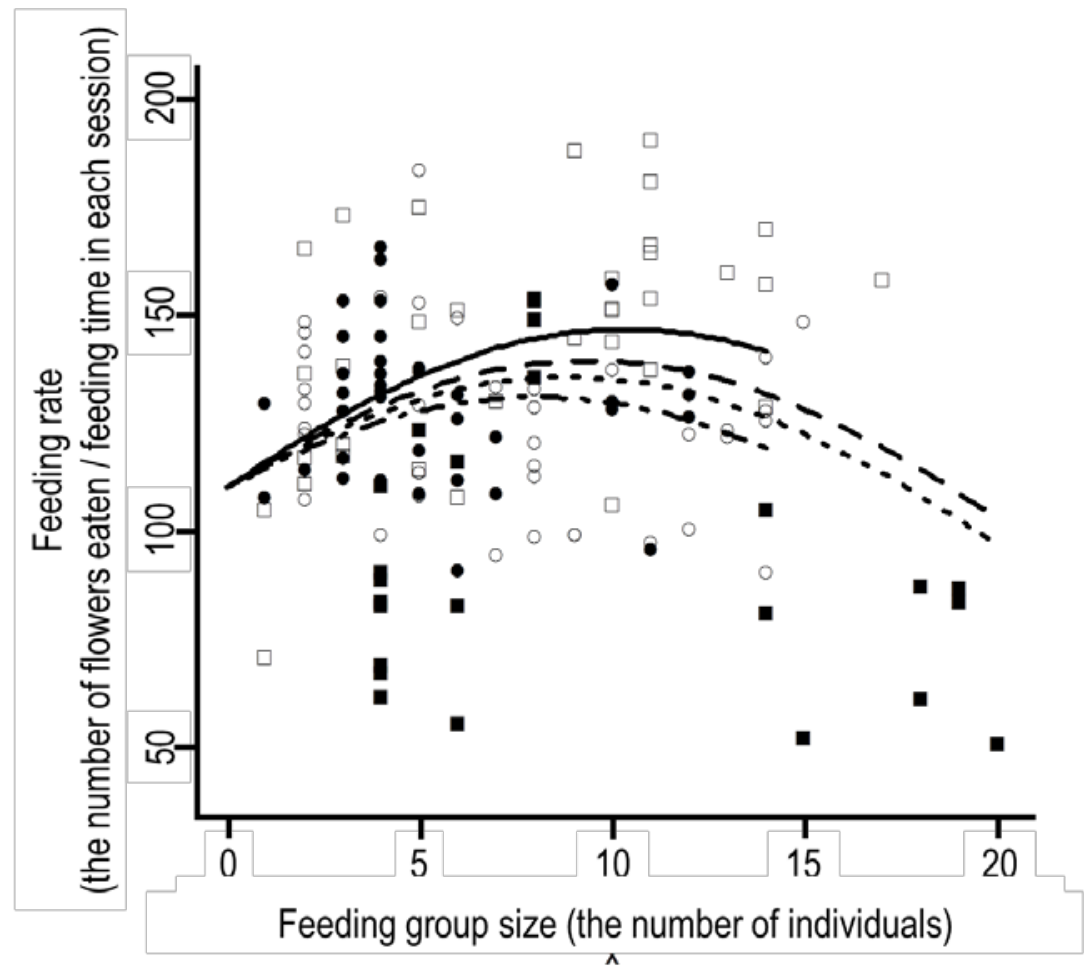

Figure 5. Relationship between feeding rate and feeding group size. The line indicates the values estimated by GLM. (• and solid line) Data from dominance rank 1; ( $\square$ and coarse dashed line) dominance rank 6; ( $\bullet$ and dotted line) dominance rank 9 ; ( $\circ$ and dotted/dashed line) dominance rank 13.

We observed five cases of aggression against focal females by other individuals and two cases of aggression against other individuals by focal females in food patches (total $425 \mathrm{~min}$ of sub-session). However, four of the five cases of aggression against focal females were not related to feeding competition, although they led to patch departure. In these cases, focal females had to flee from non-group males (three cases), or a dominant female occasionally approached a focal female solely to cause her to leave the food patch (one case). Only one of the five cases may have been the result of feeding competition. The limited sample size prevented us from examining the effects of aggression on feeding rate. However, dominance rank and the interaction between dominance rank and feeding group size were selected as explanatory variables in the best-fit model (Table 2). These variables had negative effects on feeding rate, although their coefficients were not statistically significant. Patch quality also had a negative effect on feeding rate. 


\section{Discussion}

We focused on social monitoring as a factor affecting foraging success. We hypothesized that feeding rate depends on both the cost of social monitoring and on feeding competition, which are opposite functions of feeding group size. Based on this hypothesis, we examined the following four predictions: Prediction 1 , individuals in smaller feeding groups tend to abandon food patches to follow their own group; Prediction 2 , social monitoring frequency is higher in smaller feeding groups; Prediction 3, feeding rate decreases with increasing feeding group size; and Prediction 4, the relationship between feeding group size and feeding rate is expressed as a parabolic curve.

Relationship between feeding group size and probability of 'following' (Prediction 1)

Our results suggested that individuals in smaller feeding groups tended to leave a food patch to follow group members (Table 2 and Figure 3). To avoid losing their group, primate group members must stay within a range of group dispersion (van Schaik, 1989). They visually confirm the movements of other group members (i.e., social monitoring) and then determine their own subsequent behaviour (Emery et al., 1997). Thus, individuals in smaller feeding groups, who are more likely to lose their own group, need to monitor other members carefully and follow them.

The relationship between feeding group size and social monitoring (Prediction 2), and between social monitoring and feeding rate (Prediction 3)

We predicted that individuals in smaller feeding groups are exposed to a higher risk of losing their group. Thus, such individuals need to monitor the locations and movements of other group members frequently (Prediction 2). Our results supported this prediction, finding that social monitoring frequency was higher in small feeding groups (Table 2 and Figure 4). We also predicted that social monitoring in food patches would have negative influences on foraging success (Prediction 3). In fact, the feeding rate in each session was decreased significantly by social monitoring in this study (Table 2). These results suggest that social monitoring can be costly while foraging. However, the cost decreases with increasing feeding group size.

The relationship between feeding group size and feeding rate (Prediction 4)

We hypothesized that feeding rate would depend on the costs of both social monitoring and feeding competition. These costs would be opposite functions of feeding group size. That is to say, the realized feeding rate at a given feeding group size depends on the combined costs of social monitoring and feeding competition. Therefore, we expected that feeding rate would show a parabolic relationship with feeding group size (Prediction 4). 
We verified that the two types of cost, social monitoring and feeding competition, were opposite functions of feeding group size. As described above, there was a negative relationship between social monitoring and feeding group size (Prediction 3; Table 2; Figure 4), although positive relationships between feeding competition and feeding group size have been reported in previous studies (Wrangham, 1980; van Schaik, 1983; Janson, 1985; Janson \& Goldsmith, 1995; Steenbeek \& van Schaik, 2001; Vogel $\&$ Janson, 2007).We also found that dominance rank and the interaction between dominance rank and feeding group size negatively affected feeding rate in the best-fit model (Table 2), although aggression over food resources was rarely observed. As dominance rank did not relate to social monitoring frequency (Table 2), it may reduce the feeding rate directly. These results suggest that lower-ranking females were exposed to stronger feeding competition in larger feeding groups. This would occur because subordinate individuals cannot enter good feeding locations when dominant individuals are present (Janson, 1985). In addition, we observed one patch departure due to patch depletion, which took place under the largest feeding group size. In this case, scramble feeding competition may have occurred. Thus, it is reasonable to assume that feeding competition increases with feeding group size.

As the costs of social monitoring and feeding competition were opposite functions of feeding group size, combined costs would be largest in the smallest and largest feeding groups due to the substantial costs of social monitoring or feeding competition, respectively. Therefore, a parabolic relationship between feeding group size and feeding rate was obtained in this study (Figure 5). The maximum feeding rate was realized at around 10 individuals per feeding group, i.e., that is the optimal feeding group size in this situation. Thus, feeding rate was determined by the balance between these two types of cost. Our hypothesis that feeding rate depends on the costs of both social monitoring and feeding competition, which are opposite functions of feeding group size, was supported.

\section{Reviewing the relationship between feeding rate and feeding group size}

We demonstrated that feeding rate depends on both social monitoring and feeding competition, both of which are functions of feeding group size, but with opposite effects. Results indicated three phases of feeding rate according to feeding group size. In Phase 1, the decreasing cost of social monitoring exceeds the increasing cost of feeding competition. Thus, feeding rate increases with group size under smaller feeding group sizes ( $<10$ individuals in Figure 3). In Phase 2, the increasing cost of feeding competition and the decreasing cost of social monitoring are balanced. Thus, feeding rate is relatively constant at feeding group size of around 10 individuals. In Phase 3 , the increasing cost of feeding competition exceeds the decreasing cost of social monitoring, and feeding rate decreases with feeding group size (more than 10 individuals). Thus, the relationship between feeding group size and feeding rate (positive, neutral, or negative) may vary over the three phases, according to the balance of decreasing and increasing costs.

Previous field studies have been apparently at odds over the effects of feeding group size on feeding 
rate (e.g., Whitten, 1988; Snaith \& Chapman, 2005; Kazahari \& Agetsuma, 2008). However, these studies may represent different phases of the cost balance between social monitoring and feeding competition. For example, Kazahari \& Agetsuma (2008) showed that the feeding group size of Japanese macaques had positive effects on feeding rate under rich food conditions. This situation may correspond to Phase 1. Under such conditions, feeding competition is weak, and the decreasing cost of social monitoring would exceed the increasing cost of feeding competition. In contrast, Whitten (1988) reported that the feeding rate of vervet monkeys did not vary with feeding group size. This situation may correspond to Phase 2 . Finally, Snaith \& Chapman (2005) showed that the feeding group size of red colobus monkeys had negative effects on feeding rate under limited food conditions. This situation may correspond to Phase 3. Under such conditions, feeding competition becomes severe, and the increasing cost of feeding competition would surpass the decreasing cost of social monitoring. As described above, the foraging success of animals living in groups may be affected by social factors through two different pathways, with realized foraging success depending on a balance between the two types of cost, which vary with food conditions. We can discuss optimal troop size and optimal feeding group size by considering food conditions and the balance between these two costs associated with group-living.

\section{Acknowledgements}

Dr. K. Izawa of the Investigation Committee of Japanese Monkeys in Miyagi (ICJMM) offered valuable help and information on the study site, and Ms. Y. Sugiura helped to identify individuals in the study group. The staff of the Kinkazan Koganeyama Shrine and members of ICJMM provided hospitality and assistance during the fieldwork. We greatly appreciated fruitful discussions with the staff and researchers at the Field Science Center for the Northern Biosphere, Hokkaido University. This study was partially funded by the Cooperative Research Fund of the Primate Research Institute, Kyoto University to N.K. In this study, all animal observations and vegetation surveys were carried out in compliance with current Japanese laws.

\section{References}

Agetsuma, N. (1995a). Foraging strategies of Yakushima macaques Macaca fuscata yakui. —Int. J. Primatol. 16: 595-609.

Agetsuma, N. (1995b). Foraging synchrony in a group of Yakushima macaques Macaca fuscata yakui. — Folia Primatol. 64: 167-179.

Agetsuma, N. (1995c). Rapid shifting of foraging pattern by Yakushima Macaques (Macaca fuscata yakui) in response to heavy fruiting of Myrica rubra. — Int. J. Primatol. 16: 247-260.

Altmann, J. (1974). Observational study of behaviour: sampling method. — Behaviour 49: 227-267.

Barton, R.A. (1993). Sociospatial mechanisms of feeding competition in female olive baboons, Papio anubis. - Anim. Behav. 46: 791-802.

Berger, J. (1978). Group size, foraging, and antipredator ploys: an analysis of bighorn sheep decisions. —Behav. Ecol. Sociobiol. 4: $91-99$. 
Caraco, T. (1979). Time budgeting and group size: a theory. —Ecology 60: 611-617.

Chapman, C. (1988). Patch use and patch depletion by the spider and howling monkeys of Santa Rosa National Park, Costa Rica. -Behaviour 105: 99-116.

Charnov, E.L. (1976). Optimal foraging: the attack strategy._-Am. Nat. 110: 141-157.

Clark, C.W. \& Mangel, M. (1986). The evolutionary advantages of group foraging.-Theor. Popul. Biol. 30: 45-75.

Emery, N.J., Lorincz, E.N., Oram, M.W. \& Baker, C.I. (1997). Gaze following and joint attention in rhesus monkeys Macaca mulatta. - J. Com. Psychol. 111: 286-293.

Furuichi, T. \& Hashimoto, C. (2007). Pattern of use of food patches by chimpanzees in Kalinzu Forest: analyses of ecological and sociological factors. — Primate Res. 23: S-13 (in Japanese).

Izawa, K. (1983). The ecological study of wild Japanese monkeys living in Kinkazan Island, Miyagi Prefecture. — Bull. Miyagi Univ. Educ. 18: 24-45 (in Japanese).

Izawa, K. (2005). Results of the census on Kinkazan population of Japanese macaques in 2004.- Japanese Monkeys in Miyagi Prefecture 20: 21-26 (in Japanese).

Janson, C.H. (1985). Aggressive competition and individual food consumption in wild brown capuchin monkeys Cebus apella. Behav. Ecol. Sociobiol. 18: 125-138.

Janson, C.H. (1988). Food competition in brown capuchin monkeys Cebus apella: quantitative effects of group size and tree productivity. -Behaviour 105: 53-76.

Janson, C.H. \& Goldsmith, M.L. (1995). Predicting group size in primates: foraging costs and predation risks.-Behav. Ecol. 6 : 326-336.

Janson, C.H. \& van Schaik, C.P. (1988). Recognizing the many faces of primate food competition: methods.- Behaviour 105: 165-186.

Kawamura, S. (1965).Matriarchal social ranks in theMinoo-B group: a study on rank system of Japanese macaques. — In: Japanese monkeys (Imanishi, K. \& Altmann, S.A., eds). Emory University Press, Atlanta, GA, p. 87-104.

Kazahari, N. \& Agetsuma, N. (2008). Social factors enhancing foraging success of a wild group of Japanese macaques Macaca fuscata in a patchy food environment. - Behaviour 145: 843-860.

Leighton, M. \& Leighton, D.R. (1982). The relationship of size of feeding aggregate to size of food patch: howler monkeys Alouatta palliata feeding in Trichilia cipo fruit trees on Barro Colorado Island.- Biotropica 14: 81-90.

Mitchell, C.L., Boinski, S. \& van Schaik, C.P. (1991). Competitive regimes and female bonding in two species of squirrel monkeys (Saimiri oerstedi and S. sciureus).-Behav. Ecol. Sociobiol. 28: 55-60.

de Moraes, P.L.R., de Carvalho, O. \& Strier, K.B. (1998). Population variation in patch and party size in Muriquis Brachyteles arachnoides._-Int. J. Primatol. 19: 325-337.

Nakagawa, N. (1989). Bioenergetics of Japanese monkeys Macaca fuscata on Kinkazan Island during winter._Primates 30: 441-460.

Nakagawa, N. (1990). Decision on time allocation to different food patches by Japanese monkeys Macaca fuscata. —Primates 31: 459-468.

Parker, G.A. (1978). Searching for mates._In: Behavioral ecology an evolutionary approach (Krebs, J.R. \& Davies, N.B., eds). 
Blackwell, Oxford, p. 214-244.

Saito, C. (1996). Dominance and feeding success in female Japanese macaques, Macaca fuscata: effects of patch size and inter-patch distance. — Anim. Behav. 51: 967-980.

van Schaik, C.P. (1983). Why are diurnal primates living in groups? - Behaviour 98: 120- 144.

van Schaik, C.P. (1989). The ecology of social relationships amongst female primates. — In: Comparative socioecology (Standen, V. \& Foley, R.A., eds). Blackwell, London, p. 195-218.

van Schaik, C.P. \& van Hooff, J.A.R.A.M. (1983). On the ultimate causes of primate social systems.- Behaviour 85: 91-117.

Snaith, T.V. \& Chapman, C.A. (2005). Towards an ecological solution to the folivore paradox: patch depletion as an indicator of within-group scramble competition in red colobus monkeys Piliocolobus tephrosceles. - Behav. Ecol. Sociobiol. 59: 185-190.

Steenbeek, R. \& van Schaik, C.P. (2001). Competition and group size in Thomas's langurs Presbytis thomasi: the folivore paradox revisited. - Behav. Ecol. Sociobiol. 49: 100- 110.

Sullivan, K.A. (1984). The advantages of social foraging in downy woodpeckers. — Anim. Behav. 32: 16-22.

Suzuki, M. (2006). The frequency of looking around and coo-call related to proximity in Japanese macaques. —Primate Res. 22: S-1 (in Japanese).

Terborgh, J.W. (1983). Five New World primate species: a study in comparative ecology. — Princeton University Press, Princeton, NJ.

Vogel, E.R. \& Janson, C.H. (2007). Predicting the frequency of food-related agonism in white-faced capuchin monkeys Cebus capucinus, using a novel focal-tree method. — Am. J. Primatol. 69: 533-550.

Whitten, P.L. (1988). Effects of patch quality and feeding subgroup size on feeding success in vervet monkeys Cercopithecus aethiops. - Behaviour 105: 35-52.

Wrangham, R.W. (1980). An ecological model of female-bonded primate groups. — Behaviour 75: 262-300.

Yoshii, Y. \& Yoshioka, K. (1949). Plant communities of Kinkazan Island. — Ecol. Rev. Sendai 12: 84-105 (in Japanese). 